\title{
Household food insecurity and associated factors in West Abaya district, Southern Ethiopia, 2015
}

Malla Shone ${ }^{1}$, Tsegaye Demissie ${ }^{5}$, Bereket Yohannes ${ }^{2,3,4^{*}}$ and Mulugeta Yohannis ${ }^{2}$

\begin{abstract}
Background: Subsistence farming in West Abaya district is sited in an area prone to drought. Thus, poor food security is a principal concern. But, this has been less documented. Therefore, this study aimed to determine the magnitude of household food insecurity and identify associated factors in West Abaya district, Southern Ethiopia, 2015.

Methods: Community-based cross-sectional study was done on 779 households from February to March, 2015. Out of 24 kebeles (lowest administrative units) in the district, 9 kebeles were selected randomly. Then from 9 kebeles, 15 'gots' were selected using probability proportionate to size. Gots are villages in a kebele where a kebele may have up to three of them. Data were collected using pretested structured questionnaire by trained data collectors. The study used a'Household Food Insecurity Access Scale' to measure access component of household food insecurity. Data were entered in Epi Info version 3.5.4 and exported to SPSS version 20.0 for cleaning and analysis. Binary and multivariable logistic regression was used to identify factors associated with food insecurity in the study area.
\end{abstract}

Results: The overall prevalence of household food insecurity was $38.1 \%$ in the study district. Households headed by female were more likely to be food insecure than households headed by males 'AOR $=2.1(95 \% \mathrm{Cl} 1.15,3.74)$.' Households headed by persons aged $>65$ years were 6.5 times more likely of being food insecure compared to household headed by persons aged 18-44 years, 'AOR $=6.51$ ( $95 \% \mathrm{Cl} 3.25,13)$.'The odds of households with larger family size to be food insecure was higher than households with smaller family sizes 'AOR $=2.4(95 \% \mathrm{Cl} 1.7,3.5)$.' Owning smaller farm land increases the risk of being food insecure nearly by 2 times compared to larger land size 'AOR $=1.7(95 \% \mathrm{Cl}$ $1.12,2.7)$.'Besides, households headed by uncoupled were likely to be food insecure than married 'AOR $=2.6(95 \% \mathrm{Cl}$ $1.53-4.26)$.

Conclusions: This study revealed that household food insecurity was considerable in the study area. Hence, proper attention should be given to increase food production and productivity of the farmers by improving access to farm land, strengthening the efforts of family planning and women empowerment.

Keywords: Ethiopia, Factors, Food insecurity, Household, West Abaya

\section{Background}

A household is food secure, when food is available in one's home in sufficient quality and quantity to meet all household members' nutritional requirements for productive lives [1-3]. This can be explained as access to sufficient, safe, and nutritious food to meet dietary needs

*Correspondence: bkabalo@gmail.com

${ }^{3}$ University of Bergen, Bergen, Norway

Full list of author information is available at the end of the article and food preferences for a healthy and active life of all members of a household [4]. Moreover, it has broader definitions in national, regional, and global contexts.

Household food insecurity has been endemic in Ethiopia. A historical account of famines in the country goes far back to early years (early nineteenth century). Moreover, since 2015, the country is experiencing its worst drought in over 30 years $[5,6]$. The country gets unpredictable amount and distribution of rainfall resulting in reduced food crop yields [7-11]. For poor households, 
opportunities to generate food and income are often difficult throughout the year [12]. Those households with less farm land and large families are more vulnerable [13-16]. Thus, the concept of vulnerability is an important part of food security analyses [17].

The factors for food insecurity involve demographic, socioeconomic, environmental, and other multidimensional causes [7]. However, many studies in the field have given more emphasis to the national and regional contexts, where disparities in localities and districts have been less represented. Such evidences may not verify situations at grass root level and may not reveal the extent of food insecurity problem in local contexts. The level of household food insecurity and determinants were less investigated in West Abaya district. Local version of research evidences may help stakeholders in the area to plan for possible interventions. Therefore, this study aimed to fill the information gaps by investigating the household food insecurity and factors determining household food insecurity at West Abaya. The findings of this study can be used for other similar settings.

\section{Methods}

\section{Study design and area}

Community-based cross-sectional study was conducted from February to March 2015 at West Abaya district (study area). This district is located at Gamo Gofa province (zone) in Southern Ethiopia. It is located in the West of the Lake Abaya which is the largest lake in the down side of the Great Rift Valley in Ethiopia. The total area of the district is about $1405 \mathrm{~km}^{2}$, out of which 17,437 ha is used for farming. The study area is located in 1100$2900 \mathrm{~m}$ above sea level with an annual average rainfall of $800-1600 \mathrm{ml}$ and average annual temperature of $24-30{ }^{\circ} \mathrm{C}$. There are 23 rural and 1 urban kebeles in this district with the total population of 94,576 .

Information from agricultural office of the district indicated that average size of cultivated land owned by household was about 0.2 ha. There are some assets households had though with negligible disparities by their quality and quantity among households. Those assets were: chairs, bed, jewelry, watch, television, radio, bicycle, motorcycle, refrigerator, and so on. Livelihood of this district mainly depends on mixed agriculture. Barely, wheat, sorghum, teff, maize, bean, kidney pea, false banana (Enset), banana, papaya, and other vegetables and fruits are major crops and plants grown in the area. Cattle, sheep, goat, poultry, horse, mule, and donkey were common livestock reared in the area.

\section{Study population and selection}

All households in the district were source population. We studied households selected from specific chosen gots. Thus, from 24 kebeles in the study district, nine kebeles were selected by using simple random sampling technique. Then from 9 kebeles, 15 'gots' were selected using probability proportionate to size (PPS). Standing nearly at the center of a selected 'got' randomly chosen a direction by spinning pen on the ground and we noted the direction it points when it stops. The first household was selected randomly after counting households by the direction of the earlier pen. Through the same direction subsequent households were chosen by proximity until the required sample size. This is EPI random walk method (Fig. 1).

\section{Inclusion and exclusion criteria}

All households in the selected units of the district which had household head able to talk were included. Those with household heads who were unable to communicate for different reasons (seriously ill, mental problems) were excluded.

\section{Study variables \\ Outcome variable Household food insecurity \\ Predictor variables and covariates}

- Demographic characteristics Age of household head, sex, marital status, educational status, family size, dependency ratio.

- Socioeconomic characteristics Occupations, landholding size in hectare, livestock ownership status, utilization of modern farm inputs, household income, food and non-food expense level, and other household assets (chairs, bed, jewelry, watch, television, radio, cycles, motorcycles, refrigerators, and so on).

\section{Sample size determination}

Sample size was calculated by assumptions required in Open Epi version 3.03 for the specific design. The assumptions were: anticipated frequency of outcome factor (food insecurity) in the population taken as $64 \%$ from similar study done in the country and confidence limit fixed as $95 \%$. Taking design effect as 2 and $10 \%$ none response rate, the calculated sample size for this study was 779 households.

\section{Data collection procedures}

Data were collected using pretested and structured questionnaire including 24-h dietary recall questions. Of 779 supposed study subjects, the tool was pretested on 40 (5\%) households in none selected gots before survey for validation. Data were collected by face-to-face interview of household head at his/her home by trained enumerators. Supervisors monitored data collection process daily 


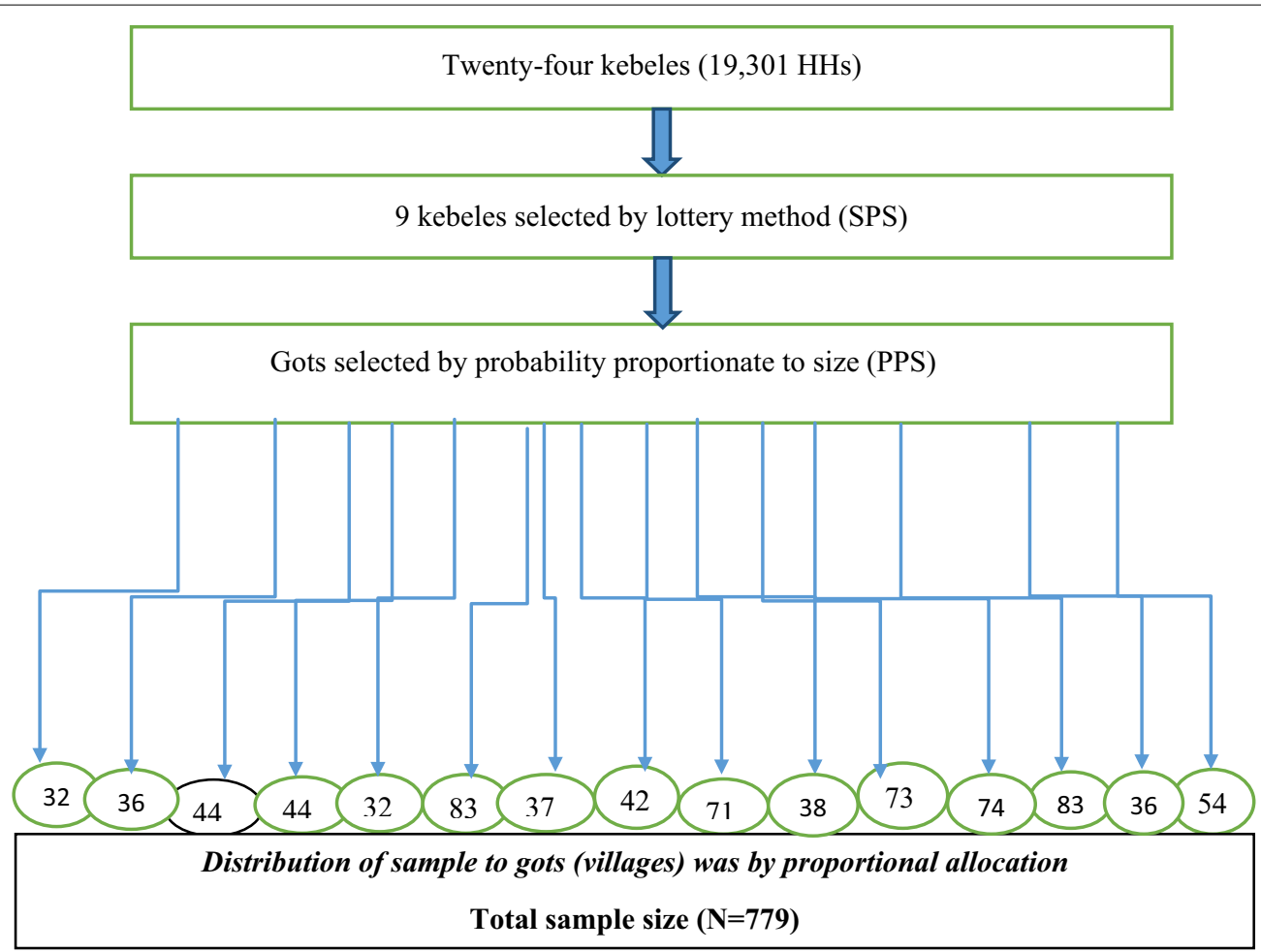

Fig. 1 Diagrammatic presentation of sampling procedure

and corrected errors at field. Before departure from the site (got), questionnaires were checked critically for completeness and consistency by supervisors.

\section{Measurement of household food insecurity}

Nine occurrence and frequency of occurrence questions/ items of FANTA 2007 were used to examine household food security scale [18]. Households were grouped into 4 categories of food insecurity using the indicator household food insecurity access prevalence. The frequency of occurrence item is recoded to ' 0 ' if the answer for occurrence item is 'No' and if 'Yes' it could be 1, 2, or 3. Thus, households were grouped based on scores achieved in specific items.

Based on the criteria, food secure households score [item one $=$ ' 0 ' or ' 1 ' and item two to nine $=$ ' 0 ']. Mildly food insecure households [(item one $=22$ ' or ' 3 ' or item two $=$ ' 1 ', ' 2 ', or ' 3 ' or item three $=$ ' 1 ' or item four $=$ ' 1 ') and item five to nine $=$ ' 0 ']. Moderately food insecure [(item three $=$ ' 2 ' or ' 3 ' or item four $=$ ' 2 ' or ' 3 ' or item five $=$ ' 1 ' or ' 2 ' or item six $=$ ' 1 ' or ' 2 ') and item seven to nine $=$ ' 0 '] and severely food insecure households score [item five $=$ ' 3 ' or item six $=$ ' 3 ' or item seven $=$ ' 1 ', ' 2 ', or ' 3 ' or item eight $=$ ' 1 , ' 2 ', or ' 3 ' or item nine $=$ ' 1 ,' ' 2 ', or ' 3 ']. The prevalence of household food insecurity is then calculated by using the number of households in each category divided by the total number of households within categories times hundred.

\section{Data management and analysis procedures}

Data were entered to Epi Info version 3.5.4 software and exported to SPSS version 20.0 for cleaning and analysis. All descriptive statistics were carried out through univariate analysis for each variable. Binary logistic regression was applied to examine the association of a single variable with food insecurity (outcome). Finally, multivariable logistic regression was carried out to identify predictors of food insecurity. Those variables having $P$ value $<0.25$ were used as a cutoff point to enter into multivariable regression. Finally, adjusted odds ratio (AOR) at 95\% CI was used as effect measure for measuring association of predictor variables and outcome controlling for potential confounders.

\section{Operational definition \\ Food insecure household}

Households with 'Yes' response to at least one of 1-9 items listed here based on household head interview were classified food insecure. These items include (1) 'Worry about not having enough food', (2) 'Unable to eat preferred food,' (3) 'Eat just a few kinds of food,' (4) 'Eat food really do not want', (5) 'Eat smaller amounts in meal', 
(6) 'Eat fewer meals in a day', (7) 'No food of any kind in household,' (8) 'Go to sleep hungry', and (9) 'Go a whole day and night without food' $[16,19]$.

\section{Household dietary diversity score (HDDS)}

It was calculated by summing up the number of food groups (cereals, vegetables, fruits, roots, animal products, etc.) consumed in the household over 24-h recall period [20-22].

\section{Wealth index}

Possessions owned by a household, based on asset-based wealth indices. The index was built using household asset data by principal component analysis.

\section{Results}

\section{Sociodemographic characteristics}

A total of 779 households participated in the study. Majority of the respondents were males $(636,81.6 \%)$. Household heads aged $18-35$ years were $282(36.2 \%)$, and most of them were married $(636,81.6 \%)$. Nearly two-thirds of the respondents (64.3\%) had no formal education. More than $50 \%$ had a family size of $\geq 4$, while the rest $363(46.6 \%)$ had $\leq 3$ family members (Table 1).

Table 1 Sociodemographic characteristics of households at West Abaya district $(N=779)$

Characteristics
Gender of household heads
Male
Female
Age distribution of household heads (years)
$18-35$
$36-44$
$45-64$
65 and above
Marital status of household heads
Married
Others (single, widowed, and divorced)
Educational status of household heads
No formal education
Formal education
Household or family size
Less or equal to 3
4 and above
Dependent members in the household
Less than or equal to 1
and above

$N(\%)$

$636(81.6)$

$143(18.4)$

$282(36.2)$

$145(18.6)$

$225(28.9)$

$127(16.3)$

$636(81.6)$

$143(18.4)$

$278(35.7)$

$501(64.3)$

$363(46.6)$

$416(53.4)$

$442(56.7)$

$337(43.3)$

\section{Socioeconomic conditions}

The result of this study shows over 329 (42\%) participants had television and nearly half of the respondents had radio, mobile phones, tables, beds, and jewelry as an asset. Motorcycle and bicycle were also owned by the participants but tiny (Table 2 ). Majority $(646,82.9 \%$ ) of the participants were farmers, followed by petty traders 53 (6.8\%). Households that lack farm lands were 151 (19\%), and from those who owned land, nearly $50 \%$ had a land size of $\leq 1.5$ ha. Concerning ownership of these assets, household wealth status was categorized by principal component analysis (PCA). Based on the principal component derived, the level of household wealth status was indexed using mean and standard deviation. Thus, households were grouped as poor, middle, and rich by means of wealth index as 275 (35.3\%), 247 (31.7\%), and 257 (33.0\%), respectively (Table 3 ).

\section{Food production and consumption}

Households that produce cereal crops were 389 (50\%), and about 237 (30.4\%) of households did not produce any type of crops. Over 328 (42\%) produce cereals and fruits in the study area. Besides, almost all households reported that they consumed cereal foods followed by vegetables, roots, and fruits in the past $24 \mathrm{~h}$ prior to this survey. Based on the findings, the consumption of animal products was reported by a smallest proportion of households (Fig. 2). Using mean score of household dietary diversity score (HDDS), households were indexed by relative miscellaneous consumption. Those households that consume relatively monotonous food groups ( $<3$ food groups) were 747 (96\%) of the participants. Moreover, households indexed as consumers of moderately diverse food groups (3 up to 4 food groups) and highly diverse food groups ( $\geq 5$ food groups) were $26(3.3 \%)$ and $6(0.6 \%)$ of the study participants, respectively (Fig. 3).

Table 2 Household possessions at West Abaya district, $2015(N=779)$

\begin{tabular}{lll}
\hline Household possessions & Yes & No \\
& N (\%) & N (\%) \\
\hline Radio & $392(50.3)$ & $387(49.7)$ \\
Television & $329(42.2)$ & $450(57.8)$ \\
Mobile telephone & $383(49.2)$ & $396(50.8)$ \\
Table & $400(51.3)$ & $379(48.7)$ \\
Chair & $528(67.8)$ & $251(32.2)$ \\
Bed & $399(51.2)$ & $380(48.8)$ \\
Jewelry & $392(50.3)$ & $387(49.7)$ \\
Motorcycle & $32(4.1)$ & $747(95.9)$ \\
Bicycle & $80(10.3)$ & $699(89.7)$ \\
\hline
\end{tabular}


Table 3 Socioeconomic conditions of households at West Abaya district $(N=779)$

\begin{tabular}{lcc}
\hline Characteristics & Frequency $(\boldsymbol{N})$ & Percentage (\%) \\
\hline Occupation of household head & & \\
Farmer & 646 & 82.9 \\
Petty trader & 53 & 6.8 \\
Others & 80 & 10.3 \\
Land ownership & & \\
No land & 151 & 17.3 \\
Less or equal to 1.5 & 348 & 46.7 \\
1.6 and above & 280 & 36 \\
Opinions on land fertility & & \\
Not fertile & 127 & 16.3 \\
Fertile & 501 & 64.3 \\
Modern farm inputs use & & \\
No & 367 & 47.1 \\
Yes & 412 & 52.9 \\
Oxen ownership & & \\
No ox & 503 & 64.6 \\
One ox & 154 & 19.8 \\
Two and above oxen & 122 & 15.3 \\
Wealth index & & 33.0 \\
Poor & 275 & 31.7 \\
Middle & 247 & \\
Rich & 257 & \\
\hline
\end{tabular}

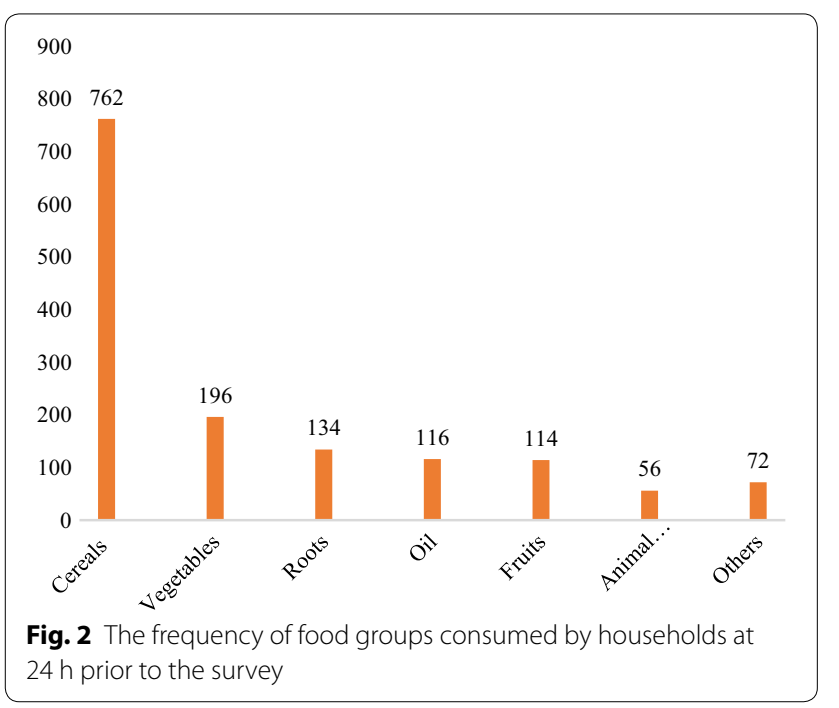

Prevalence of food insecurity at West Abaya district

Based on the finding of this study, the proportion of households gave affirmative response to worrying food inaccessibility and inabilities to eat preferred foods were 297 (38.1\%). Households reported experiencing the consumption of limited variety of foods in the past 4 weeks

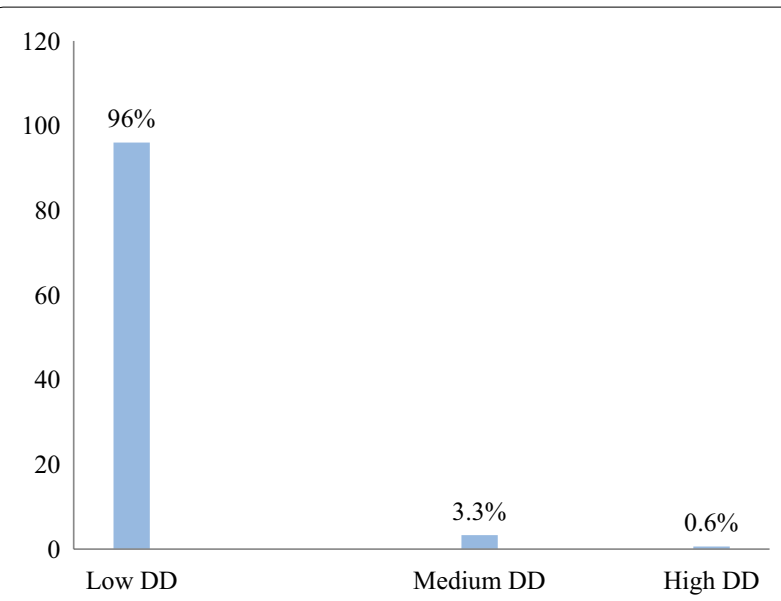

Fig. 3 Dietary diversity score by percentage in household at West Abaya district, 2015

due to lack of resources were 284 (36.5\%). Moreover, households that ate smaller meals and fewer meals were 261 (33.5\%) and 246 (31.6\%), respectively. The fraction of affirmative responses for going to bed hungry and eating no food over the whole day in the past 4 weeks were 155 (19.9\%) and 98 (12.6\%), respectively (Table 4 ).

Those nine questions were grouped into domains based on their characteristic similarities. Accordingly, the percentage of households who fall in anxiety and uncertainty domain were 297 (38.1\%), insufficient food quality domain were 297 (38.1\%), and insufficient food intake and its physical consequences domain were 269 (34.5\%) of the study participants (Fig. 4). Using scores of nine HFIAS questions, households were grouped as food secure (482, 61.9\%), mildly food insecure 125 (16\%), moderately food insecure $102(13 \%)$, and severely food insecure 70 (9\%) of the study participants (Fig. 5).

\section{Factors associated with food insecurity}

Bivariate analyses were carried out to select candidate variables for multivariable analysis. Based on set criteria, sex of household heads, age of household head, educational status, marital status, household/family size, dependent members in the household, land ownership, opinions on land fertility, oxen ownership, livestock ownership, farm input use, food crops produced and available in store, and average monthly income were selected as candidates for multivariable logistic regression. After controlling confounders, sex of household head, age category, marital status, family/household size, and land ownership had statistically significant association with household food insecurity at 95\% CI (Table 5).

Based on the findings, households headed by female were nearly 2 times more likely food insecure compared to 
Table 4 Distribution of responses to HFIAS questions at West Abaya district, 2015 ( $N=779)$

\begin{tabular}{|c|c|c|c|c|c|}
\hline \multirow[t]{3}{*}{ HFIAS questions/indicators/ } & \multicolumn{2}{|c|}{ Occurrence } & \multicolumn{3}{|c|}{ Frequency of occurrence (yes) } \\
\hline & No & Yes & Rarely & Sometimes & Often \\
\hline & $N(\%)$ & $N(\%)$ & $N(\%)$ & $N(\%)$ & $N(\%)$ \\
\hline Worried households & $482(61.9)$ & $297(38.1)$ & $87(11.2)$ & $106(13.6)$ & $104(13.4)$ \\
\hline $\begin{array}{l}\text { Were you or any household member not able to eat the kinds of foods you preferred due } \\
\text { to lack? }\end{array}$ & $482(61.9)$ & $297(38.1)$ & $101(13)$ & $99(12.7)$ & $97(12.5)$ \\
\hline Did you or any household member eat just a few kinds of food for a day due to a lack? & $495(63.5)$ & $284(36.5)$ & $94(12.1)$ & $99(12.7)$ & $91(11.7)$ \\
\hline Did you or any household member eat food that you preferred not to eat due to lack? & $534(68.5)$ & $245(31.5)$ & $81(10.4)$ & $92(11.8)$ & $72(9.2)$ \\
\hline $\begin{array}{l}\text { Did you or any household member eat a smaller meal than you felt you needed due to } \\
\text { lack? }\end{array}$ & $518(66.5)$ & $261(33.5)$ & $85(10.9)$ & $100(12.8)$ & $76(9.8)$ \\
\hline $\begin{array}{l}\text { Did you/any other household member eat fewer meals in a day because there was not } \\
\text { enough food? }\end{array}$ & $533(68.4)$ & $246(31.6)$ & $82(10.5)$ & $84(10.8)$ & $80(10.3)$ \\
\hline $\begin{array}{l}\text { Was there ever no food at all in your household because there was no resource to get } \\
\text { more? }\end{array}$ & $597(76.6)$ & $182(23.4)$ & $68(8.7)$ & $62(8)$ & $52(6.7)$ \\
\hline $\begin{array}{l}\text { Did you or any household member go to sleep at night hungry because there was not } \\
\text { enough food? }\end{array}$ & $624(80.1)$ & $155(19.9)$ & $65(8.3)$ & $52(6.7)$ & $38(4.9)$ \\
\hline $\begin{array}{l}\text { Did you/any household member go a day without eating anything because there was not } \\
\text { enough food? }\end{array}$ & $681(87.4)$ & 98 (12.6) & $39(5)$ & $25(3.2)$ & $34(4.4)$ \\
\hline
\end{tabular}

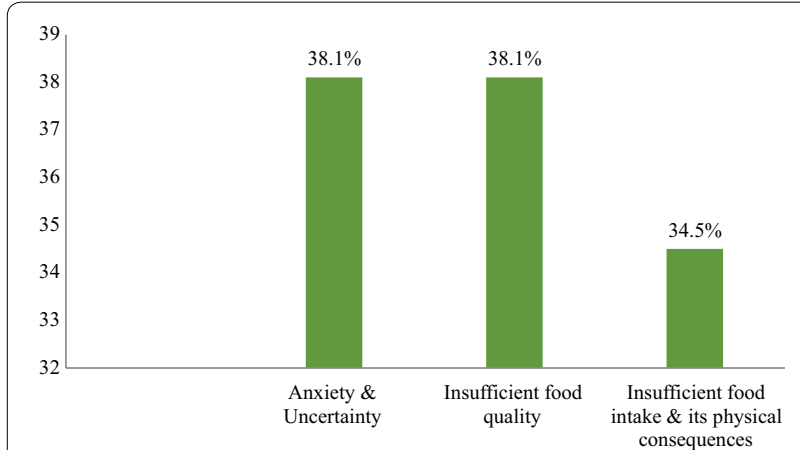

Fig. 4 Distribution of households by HFIAS domains at West Abaya district, 2015

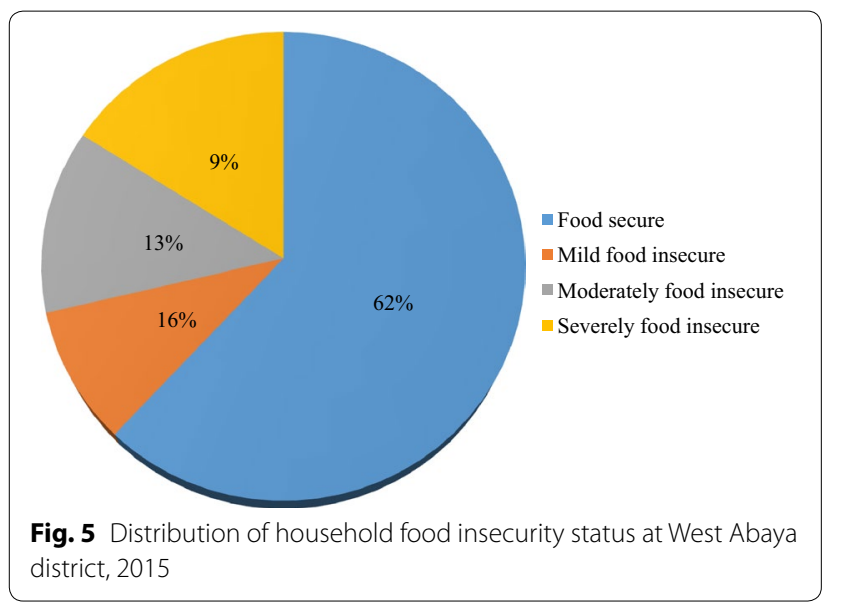

households headed by male individuals 'AOR $=2.1(95 \% \mathrm{CI}$ $1.15,3.74)$.' Households headed by persons aged $>65$ years were 6.5 times more likely of being food insecure compared to households headed by persons aged 18-44 years 'AOR $=6.51$ (95\% CI 3.25, 13)'. The finding also indicates that the odds of household with larger family size to be food insecure was 2.4 times higher than households with smaller family size 'AOR $=2.4(95 \%$ CI 1.7, 3.5)'. Land size for crop production also determines food security at the study area. Households owning smaller farm land increases the risk of being food insecure almost by 2 times when compared to relatively larger land size 'AOR $=1.7$ (95\% CI 1.12, 2.7).' Moreover, households headed by uncoupled individuals (either of widowed, divorced, or single) were likely to be food insecure than coupled individuals 'AOR $=2.6(95 \% \mathrm{CI}$ $1.53,4.26)$ ' (Table 5).

\section{Discussion}

This study assessed the magnitude of household food insecurity and associated factors at West Abaya district. The HFIAS measurement revealed 70 (9.0\%), 102 (13.0\%), and $125(16.0 \%)$ of households were severely, moderately, and mildly food insecure, respectively. The overall level of household food insecurity was found to be 297 (38.1\%) at West Abaya district. Controlling for confounders, sex of household head, age of household head, marital status, family size, and land ownership had statistically significant association with the outcome of interest.

The prevalence of household food insecurity reported in this study was comparable with study done at Shashemene district reported as 36\% [23]. But it was 
Table 5 Predictors of household food insecurity at West Abaya district, 2015 ( $N=779$ )

\begin{tabular}{|c|c|c|c|}
\hline \multirow[t]{2}{*}{ Characteristics $(N=779)$} & \multicolumn{2}{|c|}{ Household food insecurity status } & \multirow[t]{2}{*}{ AOR $(95 \% \mathrm{Cl})$} \\
\hline & Food insecure $(N=297)$ & Food secure $(N=482)$ & \\
\hline \multicolumn{4}{|l|}{ Sex of household heads } \\
\hline Male & 180 & 456 & 1 \\
\hline Female & 117 & 26 & $2.02(1.12-3.67)^{*}$ \\
\hline \multicolumn{4}{|l|}{ Age distribution of household heads } \\
\hline $18-35$ & 58 & 224 & 1 \\
\hline $36-44$ & 35 & 110 & $2.12(1.43-3.14)^{*}$ \\
\hline $45-64$ & 93 & 132 & $6.51(3.23-13)^{*}$ \\
\hline 65 and above & 111 & 16 & $7.12(3.5-14.8)^{* *}$ \\
\hline \multicolumn{4}{|l|}{ Marital status of household heads } \\
\hline Coupled (married) & 196 & 440 & 1 \\
\hline Others (single, widowed, and divorced) & 101 & 42 & $2.6(1.53-4.26)^{*}$ \\
\hline \multicolumn{4}{|l|}{ Educational status of household heads } \\
\hline No formal education & 166 & 112 & $1.3(0.82-2.00)$ \\
\hline Formal education & 131 & 370 & 1 \\
\hline \multicolumn{4}{|l|}{ Household/family size (numbers) } \\
\hline Less or equal to 3 & 88 & 275 & 1 \\
\hline 4 and above & 209 & 207 & $2.4(1.7-3.5)^{* *}$ \\
\hline \multicolumn{4}{|l|}{ Dependent members (number) } \\
\hline Less or equal to 1 & 133 & 309 & 1 \\
\hline 2 and above & 164 & 173 & $1.23(0.57-2.4)$ \\
\hline \multicolumn{4}{|l|}{ Land owned (hectares) } \\
\hline Less or equal 1.5 & 240 & 270 & $1.73(1.12-2.7)^{*}$ \\
\hline 1.6 and above & 57 & 212 & 1 \\
\hline \multicolumn{4}{|l|}{ Oxen ownership (number) } \\
\hline No ox & 193 & 310 & $0.84(0.44-1.63)$ \\
\hline One ox & 71 & 83 & $1.13(0.7-2.5)$ \\
\hline 2 and above & 33 & 89 & 1 \\
\hline \multicolumn{4}{|l|}{ Livestock ownership (TLU) } \\
\hline Less than 2.5 & 249 & 329 & $1.51(0.9-2.5)$ \\
\hline 2.5 and above & 48 & 153 & 1 \\
\hline
\end{tabular}

* $P$ value $<0.05$ significant association

** $P$ value $<0.01$ highly significant association

higher than the findings from the Humbo district (28.4\%) and lower than study from Sidama Zone [24, 25]. The difference in the findings might be due to variation in study settings and data collection seasons. The relatively lower prevalence of household food insecurity in this study might be due to the data collection period, which was harvest season in the area. This might have underestimated the magnitude of the problem. Thus, seasonal data with repeated surveys may give better evidence.

Based on HFIAS questions, the findings revealed 31.6\% households eat less than three times a day, $23.6 \%$ affirmed as did not have any food to eat, $20 \%$ of the household said that members went to sleep hungry, and $12.6 \%$ said that family members passed the whole day and night without eating anything because there was not enough food. Similar studies conducted in South Africa and Ghana had comparable findings [26, 27]. The declining trend of percentages from anxiety to not eating the whole day is because of increment in severity of the condition.

Households headed by females were 2 times more likely to be food insecure than households headed by males. The finding was in line with a study done in Nigeria [28]. Another similar study in Tigray reported finding which agrees in direction with this finding [29]. Study from Northern Ethiopia also revealed that male-headed households tend to be more food secure than femaleheaded households [30]. Culturally in the study area food production is mainly by cultivating land; however, 
females hardly cultivate. That might be the likely reason for higher food insecurity of female-headed households in the study area.

The finding of this study also indicates having smaller farm land enhances the risk of being food insecure. The usages of improved seed with fertilizers were weakly practiced in the study area based on records of district agricultural office. Additionally as indicated somewhere else $19 \%$ of households lack farm land in the study area. On the other hand, nearly half of households having land had land size of $>1.5$ ha which is far higher than average landholding $(0.2 \mathrm{ha})$ in the study area. So the reason for the relative higher food insecurity in household with smaller land size might be deprived usage of improved seed with fertilizer and lack of comparable access to farm land in the study area. Likewise, households with married couples were likely to be food secure than single, widowed, and divorced ones as their household head. That was in line with studies from Southern Ethiopia [31, 32]. This is possibly because households with married head had more access to farm land and social security than uncouples in the study area.

The current study indicated that a household with smaller family sizes tends to be food secure as compared to households with larger family sizes. Other things being constant, household food insecurity increases nearly by 2.4 times as family sizes reach $\geq 4$ compared to households with $\leq 3$ members. That was comparable with findings from Addis Ababa and Shashemene [23, 33]. Moreover, similar studies done in Malawi and Oromia regional state had also allied findings [34, 35]. At the time of increment in family size, the level of production must increase, but while household size increases, the age of household head also increases logically. So, increasing production rate which is principally by cultivation still in the study area becomes exigent.

\section{Strengths and limitations of the study}

This study used the measurement of household food access component of food insecurity. However, systematic reviews suggest that climate variables also play equally important role [7]. Households' experiences for nine very commonly seen features of food insecurity in the last 4 weeks were interviewed. Therefore, recall bias expected though small. The cross-sectional nature of our design makes arguments on association weaker, but the study used assumptions for higher sample size.

\section{Conclusions}

The findings of this study revealed a considerable proportion of households were food insecure at West Abaya district. Various factors were found to be significantly associated with household food insecurity based on the findings of this study. After controlling all other confounders, sex of household head, age of household head, marital status of household head, family size, and land ownership had major contribution for household food insecurity at the study district. Therefore, stakeholders are recommended to work on improving household food access at West Abaya district. Households with severe food insecurity need urgent response to reduce to the risk of mortality and morbidity. Moreover, intervention measures should focus on family planning and women empowerment based on evidences of the study findings. Further researches with broader scope were recommended to evaluate seasonal variation and climatic predictors of household food insecurity in the study setting.

\section{Abbreviations}

AOR: adjusted odds ratio; FANTA: Food and Nutrition Technical Assistance: HFIAS: Household Food Insecurity Access Scale; HDDS: household dietary diversity score; NORAD: Norwegian Agency for Development; PPS: population proportion to size; SENUPH: South Ethiopian Network of Universities in Public Health.

\section{Authors' contributions}

MS drafted study plan, monitored data collection, and involved in analysis and report writing. TD reviewed study plan, data analysis and wrote the manuscript. BY reviewed study plan, data analysis and wrote the manuscript. MY had valuable contribution in design, analysis, and interpretation of findings. All authors read and approved the final manuscript.

\section{Author details}

1 Present Address: District Health Office, Gamo Gofa Zone, Arbaminch, Ethiopia. ${ }^{2}$ School of Public Health, Wolaita Sodo University, Wolayta Sodo, Ethiopia. ${ }^{3}$ University of Bergen, Bergen, Norway. ${ }^{4}$ Hawassa University, Hawassa, Ethiopia. ${ }^{5}$ Wolaita Sodo University, Wolaita Sodo, Ethiopia.

\section{Acknowledgements}

Authors thank 'South Ethiopia Network of Universities in Public Health' project (SENUPH) under the 'Norwegian Agency for Development (NORAD)' for funding the project. This study would have been impossible without hosting and facilitation of the school of public health in Wolaita Sodo University. Deepest thanks go to authorities of West Abaya district offices for their cooperation. Besides, authors express their grateful to respondents.

\section{Competing interests}

The authors declare that they have no competing interests.

\section{Availability of data and materials}

The datasets analyzed during the current study were available from the corresponding author on reasonable request.

\section{Ethical consideration}

Ethical clearance was obtained from ethical review committee at college of health sciences and medicine at Wolaita Sodo University, and permission letter was obtained from district admin office. Nature of the study was fully explained to the study participants to obtain verbal consent prior to participation in the study, and information was kept confidential.

\section{Funding information}

This research was supported by NORAD_SENUPH project and Wolaita Sodo University.

Received: 2 April 2016 Accepted: 8 December 2016

Published online: 02 February 2017 


\section{References}

1. FAO. Food security information for action practical guides. 1996

2. FAO. The State of Food Insecurity in the World. Strengthening the enabling environment for food security and nutrition. Rome: FAO; 2014.

3. Belachew T, et al. Gender differences in food insecurity and morbidity among adolescents in southwest Ethiopia. Pediatrics. 2011;127(2):e398-405.

4. FAO. Food security information for action in food security concepts and frameworks. 2008

5. Dorosh P, Rashid S. Ethiopia's 2015 drought: no reason for a famine. Washington: International Food Policy Research Institute (IFPRI); 2015

6. Elazar T. Integrated community-based management of severe acute child malnutrition Studies from rural Southern Ethiopia. Uppsala: Uppsala University; 2016. p. 64.

7. Phalkey RK, et al. Systematic review of current efforts to quantify the impacts of climate change on undernutrition. Proc Natl Acad Sci USA. 2015;112(33):E4522-9.

8. Manyeruke C, Hamauswa S, Mhandara L. The effects of climate change and variability on food security in Zimbabwe: a socio-economic and political analysis. Int J Humanit Soc Sci. 2013;3(6)

9. Muller TR. 'The Ethiopian famine' revisited: band aid and the antipolitics of celebrity humanitarian action. Disasters. 2013:37(1):61-79.

10. Taye A, Mariam DH, Murray V. Interim report: review of evidence of the health impact of famine in Ethiopia. Perspect Public Health. 2010;130(5):222-6.

11. Hagos $\mathrm{S}$, et al. Climate change, crop production and child under nutrition in Ethiopia; a longitudinal panel study. BMC Public Health. 2014;14:884.

12. ACF. Seasonality: The missing piece of the undernutrition puzzle?. London: Action Against Hunger; 2013.

13. Gebrehiwot T, Vanderveen A. Coping with food insecurity on a microscale: evidence from Ethiopian rural households. Ecol Food Nutr. 2014;53(2):214-40.

14. Gray C, Mueller V. Drought and population mobility in rural Ethiopia. World Dev. 2012;40(1):134-45

15. Regassa N, Stoecker BJ. Household food insecurity and hunger among households in Sidama district, southern Ethiopia. Public Health Nutr. 2012;15(7):1276-83.

16. Endale W, et al. Food insecurity in Farta District, Northwest Ethiopia: a community based cross-sectional study. BMC Res Notes. 2014;7:130

17. Burg J. Measuring populations' vulnerabilities for famine and food security interventions: the case of Ethiopia's Chronic Vulnerability Index. Disasters. 2008;32(4):609-30.

18. Coates J, Swindale A, Bilinsky P. Household Food Insecurity Access Scale (HFIAS) for measurement of food access: indicator guide version 3; 2007. p. 1-32.

19. Hadley $C$, et al. Household capacities, vulnerabilities and food insecurity: shifts in food insecurity in urban and rural Ethiopia during the 2008 food crisis. Soc Sci Med. 2011;73(10):1534-42.
20. Wondafrash $M$, et al. Dietary diversity predicts dietary quality regardless of season in 6-12-month-old infants in south-west Ethiopia. Public Health Nutr. 2016;1-10.

21. M'Kaibi FK, et al. Effects of agricultural biodiversity and seasonal rain on dietary adequacy and household food security in rural areas of Kenya. BMC Public Health. 2015;15:422.

22. Herrador $Z$, et al. Low dietary diversity and intake of animal source foods among school aged children in Libo Kemkem and Fogera Districts, Ethiopia. PLoS ONE. 2015;10(7):e0133435.

23. Mitiku A, Fufa B, Tadese B. Emperical analysis of the determinants of rural households food security in Southern Ethiopia: the case of Shashemene District. Basic Res J Agric Sci Rev. 2012;1(6):132-8.

24. Regassa N, Stoecker BJ. Household food insecurity and hunger among households in Sidama district, southern Ethiopia. Public Health Nutr. 2011;15(7):1276-83.

25. Guja MM. Household food security status and coping strategies in Humbo Wereda, Snnprs, Ethiopia. Int J Sci Basic Appl Res IJSBAR. 2012;6:64-77.

26. Abdu-Raheem KA, Worth SH. Household food security in South Africa: evaluating extension's paradigms relative to the current food security and development goals. Afr J Agric Ext. 2011;39:91-2.

27. Aidoo R, Mensah JO, Tuffour T. Determinants of household food security in the Sekyere-Afram plains district of Ghana. 2013; 514-517.

28. Akangbe JK, et al. An analysis of yam storage strategy to promote food security in Asa local government area of Kwara state, Nigeria. Ethiop J Environ Stud Manag EJESM. 2012;5:551-75.

29. Kahsay S, Mulugeta M. Determinants of rural household food insecurity in Laelay Maichew Woreda Tigray, Ethiopia. Afr J Agric Food Secur. 2014:2(1):105-11.

30. Zerai B, Gebreegziabher Z. Effect of nonfarm income on household food security in eastern Tigrai, Ethiopia: an entitlement approach. Food Sci Qual Manag. 2011;1:15-26.

31. Onweng-Angura T, Okello-Atikoro MJ. Factors influencing household food security in Adwari sub-county in Lira district. 2009;13-34.

32. Tefera T, Tefera F. Determinants of households food security and coping strategies for food shortfall in Mareko District, Guraghe Zone Southern Ethiopia. J Food Secur. 2012;2(3):93-9.

33. Gezimu G. Determinants of food insecurity among households in Addis Ababa city, Ethiopia. Interdiscip Descr Complex Syst. 2012;10(2):159-65

34. Asenso-Okyere K, Mekonne DA, Zerfu E. Determinants of food security in selected agro-pastoral communities of Somali and Oromia Regions, Ethiopia. J Food Sci Eng. 2013;3:454-65.

35. Cohen B. Community food security assessment toolkit. J Food Sci Agric Econ. 2012:9-13.

\section{Submit your next manuscript to BioMed Central and we will help you at every step:}

- We accept pre-submission inquiries

- Our selector tool helps you to find the most relevant journal

- We provide round the clock customer support

- Convenient online submission

- Thorough peer review

- Inclusion in PubMed and all major indexing services

- Maximum visibility for your research

Submit your manuscript at www.biomedcentral com/submit 